\title{
RPG LIBERDADE: EXPERIMENTO PEDAGÓGICO PARA O ENSINO DE HISTÓRIA EM REDE
}

\author{
SALVADOR/BA JULHO/2018 \\ $\begin{array}{cc}\text { Antônio Lázaro Pereira de Souza } & \text { - UNEB - antoniosouza85@gmail.com } \\ \text { Alfredo Eurico Rodrigues Matta } & \text { - UNEB - alfredomatta@gmail.com }\end{array}$ \\ Tipo: Investigação Científica (IC) \\ Natureza: Relatório Final de Pesquisa \\ Categoria: Métodos e Tecnologias \\ Setor Educacional: EDUCAÇÃO MÉDIA E TECNOLÓGICA
}

\begin{abstract}
RESUMO
Apresenta-se o RPG Liberdade enquanto experimento pedagógico mediador do ensino de história em redes colaborativas, sendo ele uma linguagem tecnológica, de caráter lúdico, acessível aos jovens e capaz de gerar uma aprendizagem crítica e significativa. O artigo origina-se das pesquisas realizadas no grupo de pesquisa Sociedade em Rede. Pluralidade Cultural e Conteúdos Digitais Educacionais, sendo desenvolvidos inúmeros jogos que foram utilizados como instrumentos pedagógicos para a aprendizagem à distância. O RPG Liberdade foi desenvolvido sob as bases epistemológicas do socioconstrutivismo de Lev Vygotsky e dos princípios do pensar histórico de Robert Martineau. Da observância a essas teorias foi possível alcançar o objetivo de construção da proposta de solução utilizando-se a metodologia DBR, com ênfase aos pressupostos da Praxiologia, tendo em vista a indissociável relação entre o conhecimento teórico e a experiência prática, típica de pesquisas aplicadas.
\end{abstract}

Palavras-chave: RPG; Socioconstrutivismo; Ensino de História; DBR.

\section{AGRADECIMENTOS}

AO PROGRAMA DE PÓS-GRAdUAÇÃo EM EDUCAÇÃo E CONTEMPORANEIDADE PPGEDUC/UNEB, AO GP SOCIEDADE EM REDE, PLURALIDADE CULTURAL E CONTEÚDOS DIGITAIS EDUCACIONAIS E À CAPES, PELO APOIO A PESQUISA. 


\section{INTRODUÇÃO}

A utilização das tecnologias educacionais na produção do conhecimento é uma realidade com diversas possibilidades de interação social (CABELERO; MATTA, 2016). Dentre elas, os jogos digitais disponíveis em páginas Web, smartphones, computadores, tablets e consoles (videogames), tem se popularizado e gerando um crescente número de usuários, por consequência, os jogos digitais começam a ser teorizados/pesquisados e aplicados na educação, inclusive na educação infanto-juvenil, nas universidades e empresas (MATTAR, 2014).

Dentre os diversos gêneros de jogos digitais adotamos como experimento pedagógico o jogo digital multiplayer RPG - Role-Playing Game. Um jogo de narrativa, interpretação e tomada de decisão, que possui elementos básicos como o ambiente: lugar ou "mundo" em que se passa a narrativa e onde se encontram os personagens dos jogadores; sistema de regras: conjunto de regras que ordena o jogo; enredo: nele encontramos os objetivos e motivações do jogo, o enredo é divido em aventuras e campanhas; dados: junto com o sistema de regras fornece o caráter de aleatoriedade do jogo, ou seja, se um jogador deseja realizar uma ação, o êxito ou fracasso dependerá dos valores obtidos nos dados; mestre: o narrador que inicia a história e interpreta os personagens não jogáveis, chamados de NPC -Non-Player Character; PJ - personagens jogadores: são personagens inseridos na história, eles são elaborados e interpretados pelos jogadores e, por fim, as classe: arquétipo dos personagem, cada classe possui habilidades e características particulares.

Pensando em desenvolver um RPG que articulasse o socioconstrutivismo e o pensar histórico de Martineau (1997) foi modelado o RPG Liberdade, um jogo mediador do conhecimento histórico sobre a abolição da escravidão, baseado numa linguagem tecnológica de caráter lúdico, acessível aos jovens e capaz de gerar uma aprendizagem crítica e significativa para os estudantes que a ele tiverem acesso.

Aliar jogos digitais ao ensino de História é um grande desafio, a ideia aqui delineada do jogo surge como uma possibilidade de difusão do conhecimento a partir do uso das tecnologias educacionais que, neste século XXI, têm sido implementadas em muitas escolas brasileiras.

\section{REFERENCIAL TEÓRICO}

O pensar histórico é uma metodologia para o ensino de História que apresenta uma proposta de ensino no desenvolvimento do pensamento crítico e capacita educandos e 
educadores como agentes ativos na produção do conhecimento.

Devido a sua proposta metodológica, o pensar histórico possui princípios que dialogam com o socioconstrutivismo como: a) Riqueza de significado pessoal, por estabelecer uma relação entre o conteúdo e o contexto do sujeito; b) Autenticidade, por ser validado e construído pelo coletivo de maneira colaborativa; c) Engajamento para a vida social, devido à relação ensino-aprendizagem permeada de interatividade entre sujeitos e objeto de estudo. Além dos princípios para o ensino de História, o pensar histórico é baseado em quatro operações metacognitivas: formular hipótese a partir de uma situação problema, criticar as fontes de informação, interpretar as informações e chegar a uma síntese interpretativa. Essas operações levam o estudante a desenvolver três características do historiador: atitude, metodologia e linguagem (MATTA, 2001).

Para o pensar histórico, o maior objetivo da docência de História no ensino básico é o desenvolvimento e maturação dos estudantes, bem como pensar a sua historicidade.

O RPG Liberdade apresenta uma proposta convergente à pedagogia vygotskyana e ao pensar histórico, uma vez que ambos têm como princípio o engajamento dos sujeitos e o contexto, influenciando na construção e reconstrução contínua do conhecimento. Compreendendo isso e estabelecendo um diálogo entre os estudos Matta (2011) e Martineau (1997) apresentamos, a seguir, aspectos/propostas que nortearam o design cognitivo do jogo:

Quadro 1 - Aplicação do Design Socioconstrutivista ao RPG Liberdade

\begin{tabular}{|c|c|c|}
\hline Conceito & Descrição & Aplicação no jogo \\
\hline Interação Social & $\begin{array}{l}\text { São relações entre os } \\
\text { sujeitos dentro do contexto } \\
\text { do jogo. }\end{array}$ & $\begin{array}{l}\text { A partir da socialização de informações/conteúdo e } \\
\text { desafios, os jogadores e mestre compartilham } \\
\text { ideias e executando as ações no jogo, como } \\
\text { consequência da participação ativa na construção } \\
\text { do conhecimento. }\end{array}$ \\
\hline Interatividade & $\begin{array}{l}\text { Ocorre no momento em } \\
\text { que os sujeitos estão } \\
\text { interação social, uma troca } \\
\text { ou produção r de } \\
\text { conhecimento. }\end{array}$ & $\begin{array}{l}\text { Os desafios e objetivos contidos nas aventuras } \\
\text { estimulam os diálogos e as estratégias elaboradas } \\
\text { aentre mestre e jogadores, havendo permuta de } \\
\text { conhecimento e uma resolução autêntica e } \\
\text { validada por todos para os desafios propostos. }\end{array}$ \\
\hline Contextualidade & $\begin{array}{l}\text { Plano de fundo do design } \\
\text { que considera a construção } \\
\text { sócio histórica dos sujeitos }\end{array}$ & $\begin{array}{l}\text { As aventuras/campanhas construídas em } \\
\text { colaboração com os estudantes, levando em } \\
\text { consideração a sua historicidade e suas relações }\end{array}$ \\
\hline
\end{tabular}




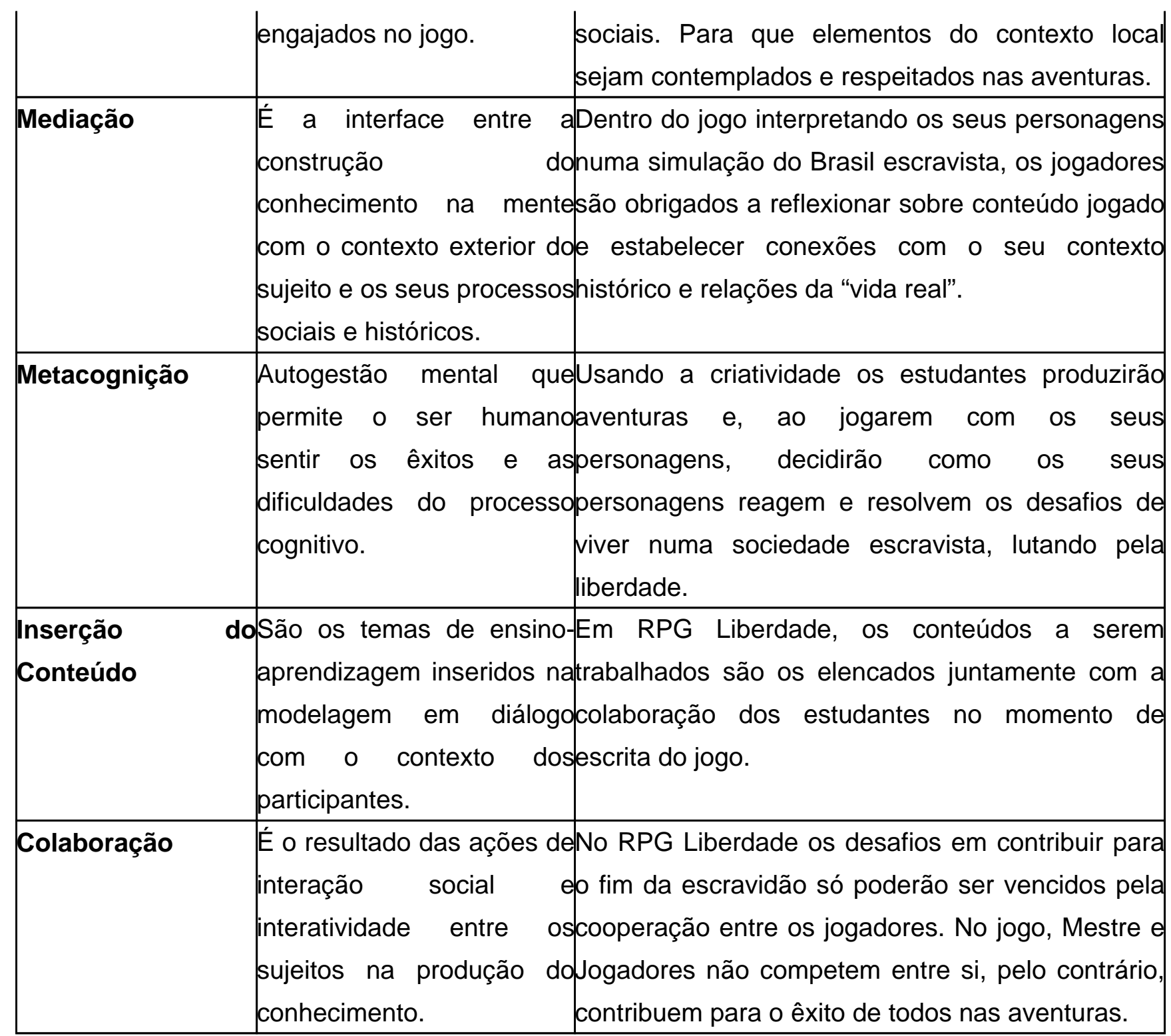

Fonte: Souza (2016, p. 42)

\section{PROCEDIMENTO METODOLÓGICO}

No intuito de atender ao objetivo proposto, a pesquisa foi lastreada pela abordagem metodológica Design-Based Research - DBR. A utilização dessa metodologia é justifica por ela apresentar métodos de pesquisa voltados para as tecnologias educativas e nos estudos sobre o uso de informática na educação, evidenciando os impactos delas na transformação da prática educacional e no cotidiano escolar (MATTA, SILVA e BOAVENTURA, 2014). A DBR é constituída de etapas de planejamento, desenvolvimento, avaliação e reavaliação das variáveis por parte do pesquisador e dos sujeitos envolvidos na pesquisa, tais características metodológicas nos conduzem à elaboração de projetos tecnológicos educacionais socioconstrutivistas, havendo assim uma aderência aos pressupostos epistemológicos da Filosofia da Práxis, Teoria 
Vigotskiana e do Modo de Pensar Histórico.

Durante toda a nossa pesquisa, consideramos as fases da DBR, desde analise do problema até o levantamento e analise dos dados, por assim ser, este estudo configurouse da seguinte maneira:

Quadro 2 - Fases da DBR aplicadas na pesquisa

\begin{tabular}{|c|c|}
\hline Fases da DBR & Aplicação na Pesquisa \\
\hline $\begin{array}{l}\text { Análise do problema por investigadores, } \\
\text { usuários e/ou demais sujeitos envolvidos em } \\
\text { colaboração. }\end{array}$ & $\begin{array}{l}\text { Definiu-se do problema, que é o } \\
\text { desenvolvimento de um jogo de RPG } \\
\text { enquanto ferramenta pedagógica para o } \\
\text { ensino da Abolição da Escravidão aos } \\
\text { estudantes da escola pública de Salvador. } \\
\text { Delinearmos o contexto sócio-histórico em } \\
\text { parceria com os sujeitos envolvidos na } \\
\text { pesquisa, professores e estudantes. }\end{array}$ \\
\hline $\begin{array}{l}\text { Desenvolvimento da proposta de solução } \\
\text { responsiva aos princípios de design, às técnicas } \\
\text { de inovação e à colaboração de todos os } \\
\text { envolvidos. }\end{array}$ & $\begin{array}{l}\text { Nesta fase, identificamos a aproximação } \\
\text { pedagógica que há entre o RPG, } \\
\text { socioconstrutivista e o modo pensar histórico. } \\
\text { Definimos o design pedagógico e iniciamos a } \\
\text { modelagem do jogo mediante a colaboração e } \\
\text { validação dos sujeitos. }\end{array}$ \\
\hline $\begin{array}{l}\text { Ciclos interativos de aplicação e refinamento em } \\
\text { práxis da solução }\end{array}$ & $\begin{array}{l}\text { O objetivo nessas fases foi à aplicação e } \\
\text { refinamento do jogo, mediante aos dados } \\
\text { analisados, assim como, estimular nos } \\
\text { estudantes uma produção autentica e } \\
\text { colaborativa do conhecimento, engajado ao } \\
\text { seu contexto e uma interpretação própria e } \\
\text { crítica da história. }\end{array}$ \\
\hline $\begin{array}{l}\text { Reflexão para produzir "Princípios de Design" e } \\
\text { melhorar implementação da solução. }\end{array}$ & $\begin{array}{l}\text { Validação e análise do jogo junto aos sujeitos, } \\
\text { seguida de uma nova aplicação e refinamento } \\
\text { do experimento e por fim, levantamento e } \\
\text { análise dos dados. }\end{array}$ \\
\hline
\end{tabular}

Fonte: Autoral 


\section{APRESENTAÇÃO E DISCURSÃO DOS RESULTADOS}

O desafio desse estudo foi transportar as características e jogabilidade do RPG presencial para o AVA - ambiente virtual de aprendizagem - assim como potencializar e aprimorar as características de simulação e colaboração com o socioconstrutivismo e o pensar histórico.

Enquanto realizávamos a análise das variáveis, chegamos a importantes conclusões de como o RPG Liberdade é eficiente para o pensar histórico e o socioconstrutivismo. Destacamos aqui alguns pontos importantes: 1으 $\mathrm{O}$ Design Cognitivo socioconstrutista como arquitetura do jogo; $2^{\circ}$ Sistema de regras e roteirização contextualizada; $3^{\circ} \mathrm{O}$ pensar histórico inicia-se na ficha de personagens, campanha e amplia-se na aventura; 4 O RPG é uma simulação critico-reflexiva.

1으 O design cognitivo socioconstrutista como arquitetura do jogo:

Para que o ambiente virtual de aprendizagem, no nosso caso o RPG Liberdade, funcionasse como esperado utilizamos o design cognitivo socioconstrutista como parâmetro de modelagem do AVA. Os elementos interação, interatividade, contextualidade, mediação, metacognição, inserção de conteúdo e colaboração, foram criteriosamente considerados durante a modelagem.

Foi a partir do design cognitivo que potencializamos o caráter colaborativo do RPG; o modo que o conteúdo foi inserido no jogo, objetivando os princípios do pensar histórico; a mediação que contribuísse na interação e interatividade dos envolvidos no experimento, e, por fim, a contextualidade, que foi alinhada entre os elementos do RPG (mestre, jogador, sistema de regras, campanha/aventura/conteúdo historiográfico).

$2^{\circ}$ Sistema de regras e roteirização contextualizada:

Quando se inicia a modelagem de um RPG, o primeiro ponto que se considera é o tema do jogo, no nosso caso, a abolição da escravidão. Para isso, contextualizamos o tema considerando os elementos influentes para entendimento da abolição da escravidão no Brasil e na Bahia. Sem a criação de um contexto prévio do tema, a roteirização da campanha e a aventura não teriam a fidelidade histórica necessária para aprendizagem do conteúdo.

Além da inserção do contexto histórico no jogo, percebemos a necessidade de inserir o contexto social dos estudantes para que as categorias do pensar histórico (significado 
pessoal, autenticidade, engajamento para a vida social) pudessem ser desenvolvidas. Foram realizadas oficinas e encontros com os estudantes e professores que objetivaram - levantamento do contexto social, discutir e validar as propostas pedagógicas/metodológicas do jogo e suas etapas de produção.

Ao fim do processo de roteirização e aplicação do RPG Liberdade, percebemos que as a aventuras produzidas em parceria com os estudantes poderia se tornar um texto pedagógico, autêntico, carregado de valor pessoal e contextualizado à realidade, uma vez que os próprios estudantes foram coautores desses textos.

Diante das possibilidades sistêmicas apresentada pelo software RPG Digital[1], o RPG Liberdade tem potencial de aplicação com estudante e professores de diferentes estados e países. Como exemplo, no futuro poderemos ter estudantes e professores brasileiros e angolanos escrevendo um jogo de RPG sobre tráfico negreiro entre os dois países.

Outro ponto importante que percebemos ao longo da aplicação do experimento pedagógico, foi à necessidade do sistema de regras ser contextualizado. Em nossa pesquisa, criamos um sistema de regras acessível aos estudantes que nunca tiveram contato com o RPG, bem como atendendo à jogabilidade mais desenvolta daqueles que são familiarizados com o jogo.

3ํำ pensar histórico inicia-se na ficha de personagens, campanha e amplia-se na aventura:

Antes de iniciarmos a aplicação do jogo imaginávamos que o pensar histórico se desenvolvia quando os estudantes começavam a jogar a aventura, mas durante a aplicação do jogo, percebemos que a partir do preenchimento da ficha de personagens os estudantes já apresentavam características do pensar histórico.

Durante o preenchimento da ficha, os estudantes criam os personagens e pensam como eles estão inseridos no contexto histórico simulado. Dentre as diversas categorias presentes na ficha, há uma que nos chama a atenção, a background ou conceito. Nesta categoria, os estudantes escrevem a história pretérita do personagem e as suas motivações dentro do jogo. Sem exceções os estudantes realizaram pesquisas históricas e criaram histórias onde destacam-se temas como etnias, gênero, direitos humanos, tráfico negreiro, resistência escrava, religiosidade e as condições de sobrevivência dos escravizados. 
Essas histórias apresentavam autenticidade, significado pessoal, e em alguns casos, engajamento para vida social. Tudo isso foi adicionado ao roteiro do jogo, e o resultado foi um engajamento maior dos estudantes no experimento.

4ํO RPG Liberdade é uma simulação critico-reflexiva:

Ao iniciarmos as pesquisas, não tínhamos uma noção muito clara da capacidade críticareflexiva do RPG aplicado em ambiente virtual. Era sabido que o RPG em modalidade presencial já apresentava essas características, devido a capacidade de interação social e interpretação dos personagens pelos participantes do jogo, mas como seria possível transportar essa dinâmica para o ambiente virtual de aprendizagem?

Para isso foi necessário criar um software que possibilitasse transportar a jogabilidade do RPG presencial para o ambiente virtual. A princípio, poderíamos utilizar um dos diversos softwares de RPG via internet, mas muitos destes exigiam dos usuários um conhecimento prévio de RPG, portanto não atendendo à realidade das comunidades escolares da Bahia; a licença de uso e o fator mais importante, ausência de um design cognitivo que atendesse ao socioconstrutivismo e ao pesar histórico. Diante de tal cenário, o grupo de pesquisa Sociedade em rede, pluralidade cultural e conteúdos digitais educacionais da Universidade do Estado da Bahia, empreendeu esforços para desenvolver o software RPG Digital modelado a partir de princípios vygotskyanos.

Após a criação do software RPG Digital, a roteirização do RPG Liberdade foi iniciada junto com os estudantes, e durante a aplicação do jogo percebemos que o pensar histórico se desenvolvia.

A campanha Liberdade aplicada no RPG Digital não se restringiu a apenas uma simulação, ou um retrato temporal da abolição. Isso pode ser comprovado quando os estudantes dentro do jogo mostraram um comportamento crítico-reflexivo sobre a temática simulada. Diversas vezes durante o experimento, os estudantes apresentavam problemas e soluções que durante a elaboração do roteiro não conseguimos prever, dando assim um caráter muito particular a cada aventura. Ao final de cada sessão, a relação simulação/aventura com a realidade social do estudante era pertinente nos diálogos entre eles com os pesquisadores.

Por fim, conseguimos vislumbrar o quão possível é desenvolver um pensar histórico com utilização de RPG em ambientes virtuais de aprendizagem. 
Apresentou-se neste artigo, as potencialidades que o jogo de RPG em plataforma virtual oferece quando utilizado na mediação do ensino de História. Cabalero (2007), já havia atestado que o RPG presencial possui caraterísticas pedagógicas de cooperação, interdisciplinaridade e socialização. Portanto o desafio desse estudo era desenvolver um Ambiente virtual de aprendizagem que as características do RPG presencial pudessem ser reproduzidas. Para responder a esse problema, dedicamo-nos a modelar o jogo RPG Liberdade, atendendo aos princípios elementares do socioconstrutivismo e do modo de pensar histórico.

Por ora, reiteramos a importância da adoção da abordagem metodológica DBR, que valoriza o contexto e o diálogo entre os envolvidos, bem como a aplicação do experimento pedagógico e suas possibilidades de refinamento, tais procedimentos nos ofereceu qualidade para o desenvolvimento do estudo e os resultados apresentados.

\section{REFERÊNCIAS BIBLIOGRÁFICAS}

CABALERO, S. S. X.; MATTA, A. E. R. Possibilidade de utilização do RPG by Moodle na educação escolar. In: GALEFFI, D.A; TOURINHO, M.A.C.; SÁ, M.R.G.B. (Org.). Educação e difusão do conhecimento: caminhos da formação. Salvador: EDUNEB, 2016. p. 259-278.

CABALERO, S. S. X. O RPG digital na mediação da aprendizagem da escrita. 2007. Dissertação (Mestrado em Educação e Contemporaneidade) - Programa de PósGraduação em Educação e Contemporaneidade, Universidade do Estado da Bahia.

CASTELLS, M. Sociedade em Rede. São Paulo: Paz e Terra, 1999.

MARTINEAU, R. L'Echec de l'apprentissage de la pensée historique à l'école secondaire. Contribuition à l'elaboration de fondaments didatiques pour enseigner l'Histoire. 1997. Tese (Doutorado em Educação) - Faculté des Sciences de L’Éducation, Université Laval, Quebec 1997.

MATTA, A. E. R.; SILVA, F. P. S. da; BOAVENTURA, E. Design-Based Research ou Pesquisa de Desenvolvimento: metodologia para pesquisa aplicada de inovação em educação do século XXI. 2014. Revista da FAEEBA - Educação e Contemporaneidade, v. 23, n. 42, p. 23-36, 2015. 
MATTA, A.E.R. Desenvolvimento de metodologia de design socioconstrutivista para a produção do conhecimento. In: GURGEL, P.; SANTOS, W. (Org.). Saberes plurais, difusão do conhecimento e práxis pedagógica. Salvador: EDUFBA, 2011. p. 237-258.

Tecnologias da aprendizagem em rede e ensino de História: utilizando comunidades de aprendizagem e hipercomposição. Brasília: Líber Livro Editora, 2006.

Procedimentos de autoria hipermídia em redes de computadores: um ambiente mediador para o ensino-aprendizagem de História. 2001. Tese (Doutorado em Educação) - Faculdade de Educação, Universidade Federal da Bahia, Salvador.

MATTAR, J. Design educacional: educação a distância na prática. São Paulo: Artesanato Educacional, 2014.

PRENSKY, M. Aprendizagem baseada em jogos digitais. São Paulo: Editora Senac, 2012.

RIBEIRO, J.B. RPG Digital e Segurança Pública: Uma proposta de aplicação pedagógica para instrução policial militar. 2016. Tese (Doutorado em Difusão do Conhecimento) - Faculdade de Educação, Universidade Federal da Bahia, Salvador.

SOUZA, A.L.P. RPG digital instrumento pedagógico para o ensino da abolição da escravidão na Bahia.2016.Dissertação (Mestrado em Educação e Contemporaneidade) - Programa de Pós-Graduação em Educação e Contemporaneidade, Universidade do Estado da Bahia.

VYGOTSKY, L. S. A formação social da mente. São Paulo: Martins Fontes, 1991.

[1] O RPG Digital, < http://rpgad.net.br/> é software desenvolvido para abrigar o RPG Liberdade. Construído no ambiente WEB SERVICE, o RPG Digital possui suporte à linguagem de programação PHP e ao banco de dados mysql com o wordpress. 